\title{
Bericht über das 8. Treffen der Alken-Preisträger in München
}

\author{
T. Block, R. Hartung, J. Breul \\ Urologische Klinik und Poliklinik der Technischen Universität München, Klinikum rechts der Isar \\ (Direktor: Univ.-Prof. Dr. R. Hartung)
}

Auf Einladung von Herrn Professor Dr. Rudolf Hartung und Herrn Professor Dr. Gregor Cevc fand vom 29. November bis 1 . Dezember 1990 das 8 . Treffen der Alken-Preisträger in München statt. In freundschaftlich-gelöster Atmosphäre befaßten sich die vorgestellten Beiträge mit aktuellen Themen der Urologie:

Jünemann $\mathrm{u}$. Mitarb. (Mannheim) berichteten über den „Einfluß eines gestörten Lipidstoffwechsels auf die Pathomorphologie und Pathogenese der vaskulären Impotenz". Nachdem Persson-Jünemann u. Mitarb. 1988 ultrastrukturelle Veränderungen wie ausgeprägte glattmuskuläre Zelldegeneration der glatten Schwellkörpermuskulatur und Veränderungen der endothelialen Beschaffenheit der Corpora cavernosa bei vaskulär impotenten Männern festgestellt hatten, wurde nun untersucht, welche Faktoren derartige extra- und intrazelluläre Veränderungen bedingen. Diese Untersuchungen erfolgten unter besonderer Berücksichtigung der Risikofaktoren Diabetes mellitus, der in Kombination mit einer erektilen Dysfunktion altersabhängig in $28-35 \%$ auftritt, und Fettstoffwechselstörungen, deren Einfluß auf die vaskuläre Impotenz ungeklärt sind.

In einer klinisch-prospektiven Studie wurden bei 65 ausgewerteten Patienten im Alter von 20 bis 70 Jahren eine komplette Impotenzdiagnostik durchgeführt und zusätzlich der vollständige Lipidstatus bestimmt. Es fanden sich zwischen den Gruppen der Patienten mit nichtvaskulärer (psychogen oder neurogen) und vaskulärer (arteriogen oder venös) Impotenz im Mittel im Referenzbereich liegende Serum-Cholesterinwerte. Erst die genauere Aufschlüsselung des Lipidstoffwechselmusters ergab bei $\mathrm{Pa}$ tienten mit vaskulärer Pathologie signifikante Unterschiede in den LDL (low-density lipoprotein) und HDL-(high-density lipoprotein)Fraktionen. Bei über $70 \%$ der vaskulär bedingten erektilen Dysfunktion fand sich bei diesen Patienten eine Hyperlipoproteinämie Typ IIa oder IIb nach Fredrickson.

Aufgrund dieser klinischen Daten wurde mit Hilfe eines aus der Arteriosklerose-Forschung bekannten Kaninchenmodells untersucht, in welcher Art die Hyperlipoproteinämie die Schwellkörperpathologie beeinflußt: 16 New-Zealand-Kaninchen wurden einer standardisierten cholesterinreichen Diät über 96 Tage unterzogen. Gruppe 1 $(n=8)$ erhielt zusätzlich einen Thromboxan-A2-Rezeptorantagonist über die gesamte Dauer der Untersuchung mit im Futter verabreicht, Gruppe $2(n=8)$ erhielt zusätzlich

Akt. Urol, 22 (1991) 247-259

(c) Georg Thieme Verlag Stuttgart · New York nur Trinkwasser. Kontrolltiere einer 3. Gruppe $(n=10)$ wurden mit normaler kaninchengerechter, cholesterinloser bzw. -armer Diät ernährt. Am Ende der Studie wurden die Versuchstiere getötet und Gewebekonzentrationen von Cholesterin, Triglyzeriden, freien Fettsäuren und Lecithin im Schwellkörpergewebe bestimmt sowie eine Elektronenmikroskopie der Schwellkörperbiopsien angefertigt.

Die Cholesterinfettgewebskonzentrationen in der nicht-behandelten und mit cholesterinreicher Diät ernährten Kaninchen zeigte signifikant erhöhte Werte um $2,1 \mu \mathrm{g} / \mathrm{ml}$ Körpergewicht im Vergleich zu den Kontrollkaninchen. Die Gruppe, die einer zusätzlichen Behandlung mit dem Thromboxan-A2-Rezeptorantagonist zugeführt worden war, zeigte Werte um 1,07 $\mu \mathrm{g} / \mathrm{ml}$ Körpergewicht. Ähnliche Ergebnisse wurden bei den Triglyzeridgewebekonzentrationen ebenso wie bei den freien Fettsäurewerten gefunden. Auffällig und interessant war, daß die Lecithinkonzentrationen im Schwellkörpergewebe in den behandelten Kaninchen sowohl gegenüber der Kontrollgruppe als auch den cholesterinreich ernährten Kaninchen um über $100 \%$ erhöht waren. Bei genauerer Auswertung der elektronenmikroskopischen Befunde fand sich in der Kontrollgruppe eine normale glattmuskuläre Schwellkörperarchitektur mit regelrechten interzellulären Kontakten und eine wie beim Menschen bekannte endotheliale Auskleidung der sinusoidalen Hohlräume. Diese Ergebnisse standen im krassen Gegensatz zu den mit einer cholesterinreichen Diät ernährten Kaninchengruppe, wobei sich eine signifikante Degeneration der glatten Schwellkörpermuskulatur fand mit Verlust der Interzellulärkontakte und einer entsprechenden Bindegewebsvermehrung. Die Zellkernkonfiguration nahm eine pleiomorphe Gestalt mit inhomogen verteiltem Chromatin an, die endotheliale Auskleidung der sinusoidalen Hohlräume ging teilweise gänzlich verloren. In einzelnen Schnitten fanden sich Fettzellinkorporationen in der glatten Muskelzelle, die in den Semidünnschnitten klarer zum Ausdruck kamen. Wenngleich sich in der ultrastrukturellen Befundung kaum Unterschiede zwischen der behandelten und nicht-behandelten cholesterinreich ernährten Gruppe fanden, so zeigte sich allerdings in den Semidünnschnitten, daß die mit dem Thromboxan-A2-Rezeptorantagonist behandelten Kaninchen eine um bis zu $40 \%$ reduzierte Fettzelleinlagerung in das Schwellkörpergewebe gegenüber der unbehandelten Kaninchengruppe aufwies.

Diese noch präliminären Ergebnisse enthalten wichtige Erkenntnisse zur Pathogenese der kavernösvenösen bzw. der vaskulären erektilen Dysfunktion. Ähnlich den Befunden am Menschen fanden sich in der Gruppe der mit cholesterinreicher Diät ernährten Kaninchen ultrastrukturelle Veränderungen, die insbesondere die glatte 


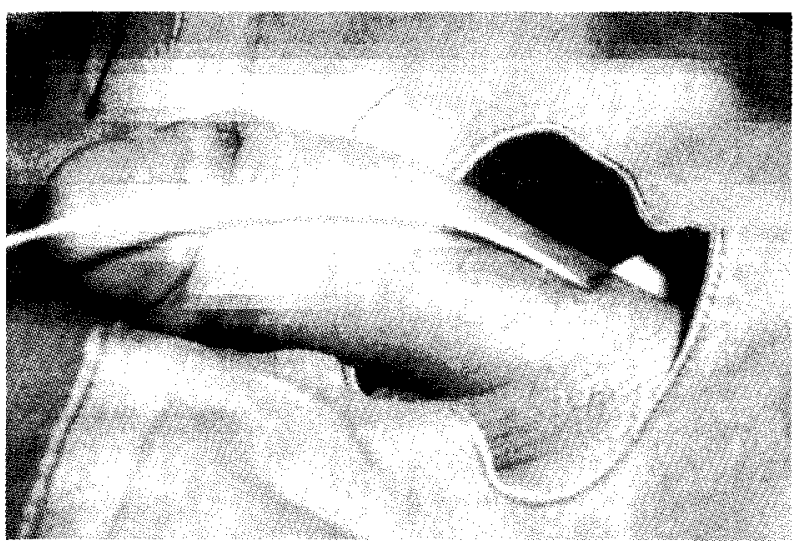

Abb. 1 Transpenile Punktion der tiefen Dorsalvene
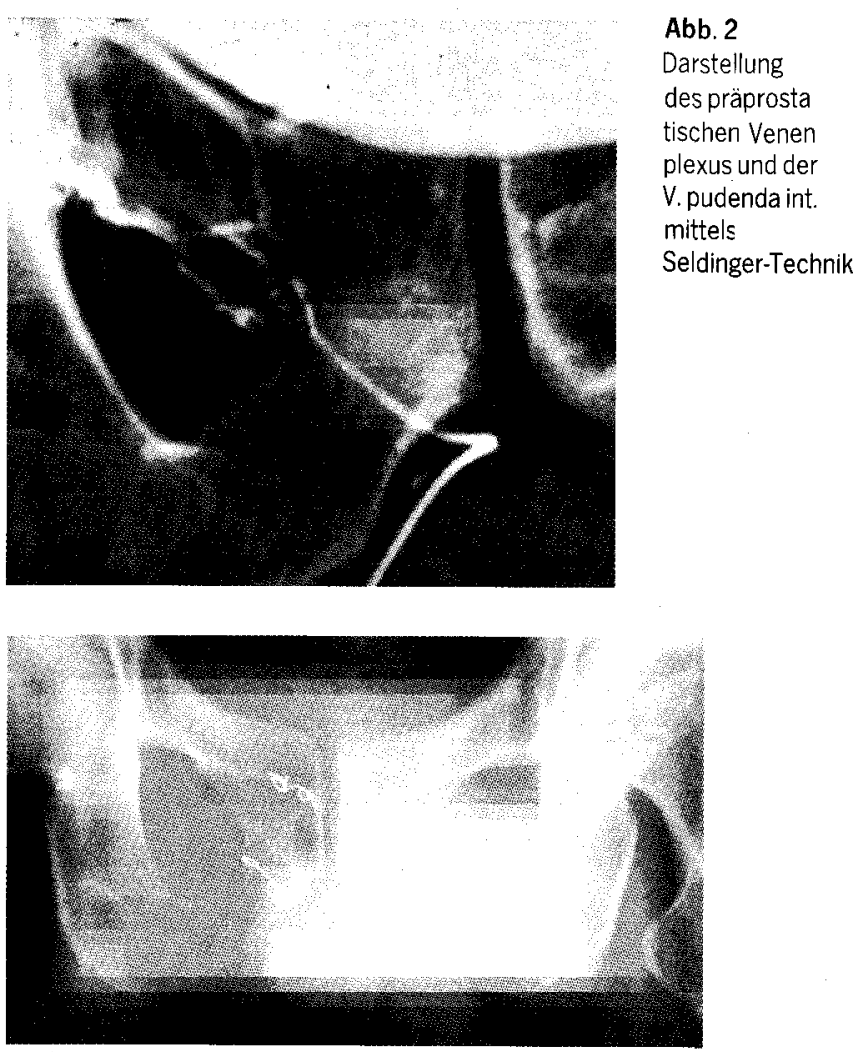

Abb. 3 Okklusion größerer Venen mittels Platinspiralen

Schwellkörpermuskulatur betrafen. Auch zeigte sich erwartungsgemäß, daß die Fettgewebskonzentrationen, ähnlich dem histologischen Bild in den cholesterinreich ernährten Kaninchen, drastisch erhöht waren. Jünemann kam zu der Schlußfolgerung, daß ein gestörter Lipidstoffwechsel eine entscheidende Rolle in der Pathogenese der kavernösen glattmuskulären Zelldegeneration spielt und einer der Hauptfaktoren für das Entstehen der sogenannten kavernös-venösen erektilen Dysfunktion darstellt. Der anhand der biochemischen Untersuchungen nachgewiesene reversible Effekt des gestörten Lipidstoffwechsels durch die additive Behandlung mit einem Thromboxan-A-Rezeptorantagonist könnte in Zukunft eine bedeutsame Rolle für die Behandlungsstrategie bei vaskulärer erektiler Dysfunktion darstellen.
Müller (Mainz) stellte „Erfahrungen, Indikationen und Grenzen der transpenilen venösen Okklusion beim venösen Leck" vor: Viele Patienten mit sekundärer erektiler Dysfunktion haben als mögliche Ursache ein sogenanntes venöses Leck. Die Erfahrungen mit der chirurgischen Ligatur der tiefen Dorsalvenen des Penis waren bei längerem Verlauf sehr enttäuschend. Alternativ werden z. B. von Lue aufwendige mikrochirurgische Verfahren oder aber die komplette Ligatur beider Crura des Penis beschrieben.

Um die hierbei auftretenden möglichen Komplikationen zu reduzieren und speziell die im kruralen Bereich auftretenden venösen Lecks zu verschließen, wurde der perkutane transpenile Weg über die tiefe Dorsalvene gewählt (Abb. 1). Mit Hilfe der Seldinger-Technik können dann in Lokalanästhesie der präprostatische Venenplexus und die Vena pudenda interna dargestellt werden (Abb. 2). Größere Venen, die die aus den Corpora cavernosa austretenden Venen aufnehmen, wurden mit dünnen Kathetern entriert und mit Platinspiralen okkludiert (Abb. 3). Distal der Okklusion wurde entweder Varikozid ${ }^{\circledR}$ oder heißes Kontrastmittel injiziert.

War die Punktion der tiefen Penisvene nicht möglich, konnte man auch retrograd über die Vena femoralis oder durch Punktion der Vena jugularis mit dünnen Sonden bis in den präprostatischen Plexus vordringen.

Bei 27 Patienten wurden insgesamt 57 Eingriffe durchgeführt. Die maximale Nachbeobachtung betrug 33 Monate. Alle Patienten waren präoperativ SKATnon-Responder. Nach einer Zwischenauswertung im September 1989 mit insgesamt 17 Patienten lag die Erfolgsrate bei 65\% (6 Patienten mit Spontanerektionen, 5 Patienten mit Erektionen nach SKAT).

Bezogen auf die 29 zur Zeit auswertbaren Patienten lag die Erfolgsrate bei $55 \%$ (Spontanerektionen: 5 Patienten; Erektionen nach SKAT: 11 Patienten). 7 Patienten wurden bisher nicht mit SKAT ausgetestet.

Erfreulich war es, daß nach einem weiteren Jahr Nachbeobachtung der ersten 17 Patienten sich nur einer der Patienten mit Spontanerektionen verschlechterte und momentan zum Verkehr nur nach SKAT-Injektionen in der Lage ist. 4 dieser Patienten wurden je einmal nachembolisiert. In der Gruppe der primären Versager ließ sich keine Änderung erzielen, obwohl je 1 Patient zweimal bzw. einmal nachembolisiert wurde.

Noch sind die Erfahrungen und insbesondere die Nachbeobachtungszeit zu kurz, um diese Methode den operativen Verfahren als überlegen zu bewerten. Das Verfahren ist jedoch in Lokalanästhesie durchführbar, der Patient muß nur 24 Stunden nach Therapie flach liegen und kann am nächsten Tag entlassen werden. Die Methode ist jederzeit wiederholbar und zumindest vom retrograden Zugangsweg her auch für solche Patienten geeignet, bei denen bereits eine operative Intervention fehlgeschlagen ist.

Voraussetzung einer venösen Embolisation sind gute arterielle Durchblutungsverhältnisse, die mittels 
Duplex-Sonographie bestätigt werden. Trotzdem läßt sich das postoperative Ergebnis nur schwer voraussagen. Negative Faktoren sind sicherlich systemische Erkrankungen wie Diabetes mellitus und generalisierte Arteriosklerose der Gefäße sowie fortgeschrittenes Alter der Patienten. Als ungünstiger Faktor erwies sich weiterhin der primäre Nachweis eines kavernosospongiösen Shunts (Darstellung der Glans penis und Corpus spongiosum bei der Kavernosographie). Ziel muß es sein, durch eine geeignete Patientenauswahl und noch strenger zu definierende Indikationskriterien jene Patienten zu selektionieren, die aller Wahrscheinlichkeit nach von der vorgestellten Methode profitieren dürften.

Wespes u. Mitarb. (Brüssel) gingen auf die „Wichtigkeit der Schwellkörperbiopsie in der Diagnose und Therapie der Impotenz" ein. Er führte aus, daß Veränderungen der glatten Schwellkörpermuskulatur bedeutsam in der Pathogenese der erektilen Dysfunktion sind. Da eine Reduktion dieser Muskelfasern die Ursache einer Impotenz sein kann, wurden mittels Computeranalysen ihre Zahl bei Männern mit unauffälliger Potenz und Patienten mit arteriell oder venös bedingter erektiler Dysfunktion bestimmt. Gleichzeitig wurden auch postmortale Studien durchgeführt, um den potentiellen klinischen Stellenwert einer kleinen Schwellkörperbiopsie durch Vergleich mit Exzisionen, die postmortem an verschiedenen Stellen der Corpora cavernosa entnommen wurden, zu überprüfen.

5 Männer mit unauffälligen Erektionen hatten kongenitale Penisdeviationen. Die Gruppe der 30 impotenten Männer bestand aus 20 Patienten mit reinem kavernosovenösem Leck und 10 Männern mit allein arteriell bedingter erektiler Dysfunktion. Ein kavernosovenöses Leck wurde diagnostiziert, wenn nach intrakavernöser Applikation von $60 \mathrm{mg}$ Papaverin die FluBraten zur Entwicklung und Aufrechterhaltung einer Erektion $40 \mathrm{ml} / \mathrm{min}$ bzw. $10 \mathrm{ml} / \mathrm{min}$ überschritten; die penile Pharmakoangiographie ergab keinen Hinweis für das Vorliegen einer arteriellen Insuffizienz.

Die Schwellkörperbiopsien wurden während der operativen Korrektur kongenitaler Penisdeviationen, nach venenchirurgischen Eingriffen und bei Implantation von Penisprothesen aus dem mittleren Drittel des Corpus cavernosum entnommen. Die immunhistologische Färbung der glatten Muskelfasern erfolgte nach der unlabeled Peroxydase-Antiperoxydase-Technik nach Steinberger (1979). Das Biopsiematerial wurde mit $\mathrm{H}_{2} \mathrm{O}_{2}$, Schafserum und Ratten-anti-Human Desmin-Antikörpern inkubiert. Desmin ist das hauptsächliche intermediäre Filament in reifen Skelett-, Herz- und Schwellkörperzellen. Danach erfolgte eine Inkubation mit Schwein-anti-Ratten-Immunglobulin und mit Peroxydase-Antiperoxydase. Es wurde der Prozentanteil der glatten Muskelfasern in einem definierten Bereich in fünf aufeinanderfolgenden Gesichtsfeldern mittels Computeranalyse nach immunhistologischer Färbung mit Anti-Desamin bestimmt.

Weiter wurde eine Vergleichsstudie an 5 Männern zwischen 55 und 80 Jahren, die an verschiedenen Ursachen ohne Beteiligung des Genitaltrakts verstarben, durchgeführt, um festzustellen, ob kleine, während der Operation entnommene Probeexzisionen die Schwellkör- permorphologie repräsentativ darstellen oder ob Unterschiede bestehen. Dies erfolgte erneut mittels Computeranalyse nach immunhistochemischer Färbung mit Antidesamin.

Nach diesen Untersuchungen von Biopsien von Patienten und Leichen wurde eine neue ambulante $\mathrm{Me}$ thode entwickelt zur Entnahme von Schwellkörperbiopsien, die zur Evaluation impotenter Patienten vor einer chirurgischen Korrektur der erektilen Dysfunktion diente. Die Biopsien wurden nach Lokalanästhesie der Penishaut oder während der Allgemeinnarkose aus dem balanopräputialen Übergang an der dorsolateralen Seite entnommen. Nach einer 2-3 mm Hautinzision wurde die Biopsienadel longitudinal durch die Tunica albuginea in das Corpus cavernosum eingeführt und das Biopsiematerial in Boin-Lösung eingelegt. Es kann mehr als eine Punktion durchgeführt werden, um repräsentatives Material zu gewinnen. Dopplersonographien der Schwellkörperarterien erfolgten vor und nach Biopsie. Das Gewebe wurde nach Masson-Trichrome-Methode gefärbt. Diese Biopsien wurden mit solchen, die während der Implantation einer Penisprothese sowie denen, die postmortem gewonnen wurden nach immunhistologischer Färbung mit Anti-Desamin verglichen.

Der Prozentanteil der Schwellkörpermuskelfasern in Patienten mit unauffälliger Erektion betrug zwischen 40 und $52 \%$. Bei Patienten mit korporaler venenokklusiver Dysfunktion fand sich eine Reduktion auf 19-36\%. Die Abnahme der glatten kavernösen Muskelfasern korrelierte mit dem Ausmaß des venösen Lecks. Bei Patienten mit arteriell bedingter erektiler Dysfunktion zeigte sich eine Minderung der glatten Muskelfasern auf $10-25 \%$.

Die Computeranalyse des Prozentanteils des Schwellkörpergewebes war nicht signifikant unterschiedlich bei den postmortem-Entnahmen im proximalen und distalen Anteil des Schwellkörpers.

Bei den ambulant entnommenen Biopsien konnte das Schwellkörpergewebe anhand der glatten intrakavernösen Muskelfasern, Arterien, Nerven und Kollagen leicht identifiziert werden. Von allen Patienten konnte repräsentatives Gewebe zur histologischen Analyse erhalten werden, die Repräsentativität war gleich der operativ gewonnener Biopsien. Nur bei einem Patienten mußten zwei Biopsien durchgeführt werden. Der Anteil der Schwellkörpermuskelfasern war ähnlich der mittels Biopty-gun-Biopsie und der offenen Biopsie, die während einer Penisprothesen-Implantation oder bei Leichen gewonnen wurde.

Keiner der ambulant biopsierten Patienten hatte bei der Biopsie Schmerzen oder benötigte postoperativ ein Schmerzmittel. Es wurden weder Hämatom noch wesentliche Blutungen beobachtet. Die Dopplersonographie nach Biopsie ließ keine Läsionen kavernöser Arterien erkennen.

Diese Untersuchung quantifiziert den Anteil der glatten kavernösen Muskelfasern in potenten und impotenten Männern. Es wurde eine Reduktion ihres Anteils bei impotenten Männern beobachtet, die die Ursache der erektilen Dysfunktion erklären könnten. Die Erektion ist abhängig von der Compliance der sinusoidalen Räume, was aus 
einer Relaxation der Schwellkörperfasern resultiert. Die Minderung ihres Anteils führt zu einer Erhöhung intrazellulärer Bindegewebsfasern und könnte daher Gewebeschwäche induzieren, die die normale Physiologie der Schwellkörperfasern stört. Eine Verschlechterung des Kompressionsphänomens im unterhalb der Tunica albuginea liegenden Plexus kann zu einer venös-okklusiven Dysfunktion des Schwellkörpers führen. Diese Hypothese scheint durch die Beobachtung bestätigt zu sein, daß man eine Korrelation zwischen Minderung der Schwellkörpermuskelfasern und dem Ausmaß des kavernösen Lecks beobachtet.

Wodurch wird nun eine Abnahme der Schwellkörpermuskelfasern verursacht? Toxische Partikel oder chronische Ischämie führen zu einer Schädigung der Muskelzellen. Das höhere Alter der untersuchten Patienten mit vaskulär bedingter Impotenz würde - verglichen mit den jungen Patienten mit kongenitaler Penisdeviation - diese Minderung erklären. Biopsien jüngerer Patienten mit kavernösem Leck wurden jedoch ebenfalls analysiert.

Zur Frage, ob die Biopsie aus dem mittleren Bereich des Penis repräsentativ ist, führte Wespes aus, daß man keine signifikanten Unterschiede bei Probeexzisionen postmortem zwischen proximalen und distalen Entnahmestellen feststellte.

Da bisher histologische Untersuchungen des erektilen Gewebes an während einer Operation gewonnenen Biopsien durchgeführt wurden, erfolgte der Versuch der Entwicklung einer neuen Methode, um Biopsien präoperativ zu entnehmen.

Der Gebrauch der Biopty-Gun zur Entnahme von Schwellkörperbiopsien unter Lokalanästhesie wurde eine einfache und zuverlässige Methode, um genügend Gewebe zur histologischen Untersuchung zu gewinnen. Der Punktionsort ist wichtig, um sekundäre subkutane Hämatome zu vermeiden. Die mittels Biopty-Gun erhaltenen Biopsien korrespondieren mit den während einer Operation entnommenen. Das Biopsiematerial sollte etwa die Größe haben wie bei vaskulären Rekonstruktionen durchgeführten Probeexzisionen. Die entwickelte Methode ist auch kostengünstig und konnte ambulant in Lokalanästhesie durchgeführt werden. Immer wieder wird die Frage diskutiert, ob man bei impotenten Männern eine Revaskularisation oder Venenkorrektur vornehmen soll. Wespes empfahl die Operation, wenn genügend intakte kavernöse Muskelzellen nachweisbar sind. Die Quantifizierung des muskulären Anteils erlaubt die Beantwortung der Frage; z.Z. werden die Patienten, die venenchirurgisch korrigiert wurden mit dem Anteil der kavernösen Muskelfasern ihrer Schwellkörperbiopsien untersucht. Es muß der Prozentanteil kavernöser Muskelfasern bestimmt werden, bei dem eine operative Rekonstruktion möglich ist.

Die Computeranalyse nach immunhistologischer Färbung (Anti-Desmin-Antikörper) erlaubt die Quantifizierung des Anteils kavernöser Muskelfasern in potenten und impotenten Männern. Diese Untersuchungen könnten in Zukunft eine bessere Selektion impotenter Patienten für vaskuläre Rekonstruktionen erlauben.
Colleselli u. Mitarb. (Innsbruck) stellten eine in Zusammenarbeit mit dem anatomischen Institut der Universität durchgeführte Studie über die „Neuroanatomie der membranösen Harnröhre" vor. Dabei konnte der Verlauf der Pars membranacea urethrae durch den Beckenboden und die Beziehung der sie begleitenden bzw. versorgenden Gefäße und Nerven präpariert werden.

Der Beckenboden wird von zwei Muskelsehnenplatten gebildet, die sich teilweise überlappen. Der größere, kranial gelegene und annähernd trichterförmige Anteil, das Diaphragma pelvis, besteht aus dem M. levator ani und dem M. coccygeus sowie den Fasciae diaphragmatis pelvis superior et inferior. Die kleinere Platte, das nahezu plan verlaufende trapezförmige Diaphragma urogenitale mit den Fasciae diaphragmatis urogenitalis superior et inferior besteht dorsal aus den $\mathrm{Mm}$. transversus perinei superficialis et profundus und im ventralen Abschnitt aus dem Ligamentum transversum perinei.

Unter Centrum tendineum versteht man die kleine, derbe, aus Bindegewebe und reichlich glatter Muskulatur bestehende Gewebeplatte, die den rektourethralen Raum nach kaudal abschließt. Die Inzision des Centrum tendineum, als kaudale Begrenzung des „Perinealkeils“, führt zur Darstellung der Pars membranacea urethrae. Die A. pudenda interna verläßt am Hinterrand des Diaphragma urogenitale den Canalis pudendalis. Entlang ihrem Verlauf zwischen oberer und unterer Fascia diaphragmatis urogenitalis gibt sie eine Reihe von Ästen ab. Der tiefe Endast der A. pudenda interna durchzieht in der Folge den M. transversus perinei profundus und teilt sich in die A. dorsalis penis und A. profunda penis auf. Vom tiefen Endast der A. pudenda interna entspringt die A. bulbi penis. Sie gelangt im Diaphragma urogenitale zum Bulbus penis, wobei sie Äste zur Muskulatur und zur Pars membranacea abgibt.

Die V. dorsalis penis profunda verläuft entlang dem Dorsum penis und tritt zwischen Ligamentum transversum perinei und Ligamentum arcuatum pubis hindurch. Bereits an der Durchtrittsstelle oder kurz darauf bildet sie 2 mächtige Venenäste aus, die in der Folge in den Plexus venosus prostaticus einmünden.

Der Plexus pelvinus erhält parasympathische Fasern über die Nn. erigentes, die bereits 1863 von Eckhardt beschrieben worden sind und stellt eine sagittale Platte dar, die lateral von Prostata und Rektum verläuft. Er versorgt mit seinen viszeralen Ästen Harnblase, Harnleiter, Samenleiter, Prostata, Urethra, Schwellkörper und Rektum. Laterokaudal der Prostata liegen die das Corpus cavernosum versorgenden Nn. cavernosi. Es handelt sich bei diesen Nerven um extrem feine, und daher nur mit der Lupenbrille ausreichend darstellbare Strukturen. Da die Nn. cavernosi vom Plexus pelvicus ausgehen, ist makroskopisch keine Unterscheidung sympathischer und parasympathischer Anteile möglich. Am Apex der Prostata ziehen diese Nerven nach ventrolateral, durchbohren das Diaphragma urogenitale und verlaufen nun lateral der Pars membranacea urethrae. Weiter konnten die Nervenäste, ausgehend vom Plexus pelvicus bis hin zur membranösen Harnröhre, dargestellt werden. Diese Präparationen wurden an fetalen Präparaten durchgeführt. Fünf Feten dienten ausschließlich der Darstellung jener Nerven, die die membranöse Harnröhre ver- 


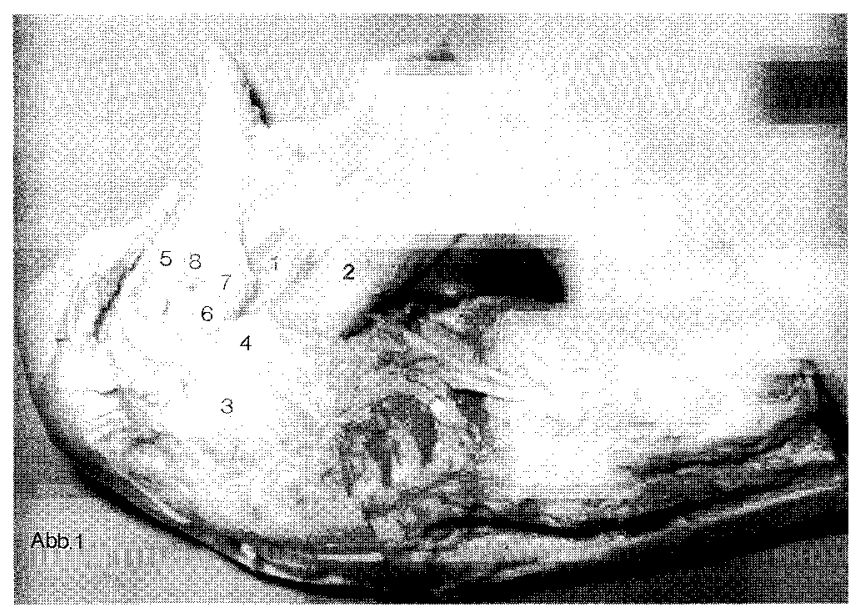

Abb. 4 Seitliche Ansicht der Beckenorgane im anatomischen Präparat, das linke Os coxae wurde entfernt. Der M. bulbospongiosus wurde in der Medianen inzidiert und nach kranial geklappt. Dadurch kommt der Bulbus penis zur Darstellung. Weiter wurde das Diaphragma urogenitale durchtrennt und somit die membranöse Harnröhre freipräpariert. Subfaszial zeigt sich der Plexus pelvinus

Abb. 4 1. Symphyse, 2. Harnblase, 3. Rektum, 4. Prostata, 5. Bulbus penis, 6. membranöse Harnröhre, 7. M. transversus perinei profundus, 8. M. bulbospongiosus, 9. Nervenäste des Plexus pelvicus zur membranösen Harnröhre

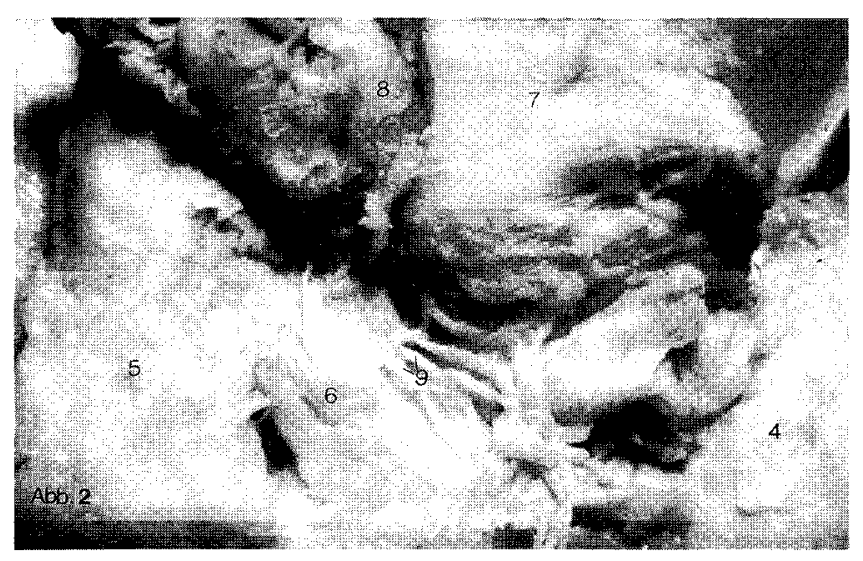

Abb. 5 Darstellung des Bereiches von Bulbus penis, membranöser Harnröhre und Prostata. Man erkennt deutlich die Einmündung der Nerven aus dem Plexus pelvicus und seinen Ästen in das Bindegewebe der membranösen Harnröhre Abb. 5 1. Symphyse, 2. Harnblase, 3. Rektum, 4. Prostata, 5. Bulbus penis, 6. membranöse Harnröhre, 7. M. transversus perinei profundus, 8 . M. bulbospongiosus, 9. Nervenäste des Plexus pelvicus zur membranösen Harnröhre teils durch Äste der Nn. prostatici. Alle Äste zur membranösen Harnröhre verlaufen lateral und kranial der Harnröhre. Dabei erreichen sie das periurethrale Bindegewebe im distalen Abschnitt der Urethra (Abb, 5, 6). Durch die mediane Inzision des M. bulbospongiosus und anschließende Spaltung der Fasern des M. transversus perinei profundus erhält man die ausgezeichnete Exposition des Bulbus penis und der membranösen Harnröhre. Nach vorsichtigem Abschieben der viszeralen Beckenfaszie zeigen sich die Nerven zur membranösen Harnröhre in der beschriebenen Lokalisation.

Aus 6 weiteren Feten, die für die histologische Studie vorgesehen waren, mußten zunächst Präparatblöcke, die Prostata, membranöse Harnröhre, Bulbus penis und Rektum beinhalteten, entnommen werden (Durchschnittsgröße $2 \times 1,5 \times 1,5 \mathrm{~cm})$. Diese wurden nach üblicher Fixierung in Paraffin eingebettet und in weiterer Folge in Schnittserien untersucht. Von jedem Block wurden ca. 600 Schnitte angefertigt. Aus diesen Serien erfolgte die Beurteilung jener Schnitte, die den Bereich der membranösen Harnröhre beinhalteten. Alle Schnitte wurden jeweils mit Hämatoxylin-Eosin und Azan gefärbt. Deutlich zeigt sich, daß die Nerven zur Urethra im lateralen Bereich der Harnröhre liegen. Durch Ausdehnung der Schnittserien in Richtung Rektum kann der Plexus pelvicus dargestellt werden. Hierin zeigt sich eine Übereinstimmung mit der Makroskopie. Der N. pudendus wird aus den Rr. anteriores der Spinalnerven $\mathrm{S} 2-\mathrm{S} 4$ gebildet und nimmt einen anderen Verlauf als das autonome Nervengeflecht des Plexus pelvicus. Er zieht zunächst durch das Foramen infrapiriforme und verläuft dorsal der Spina ischiadica, durch das Foramen ischiadicum minus in den Canalis pudendalis in der lateralen Wand der Fossa ischiorectalis. Entlang seinem Verlauf durch diesen Kanal begleitet er die Vasa pudenda interna und teilt sich bei Erreichen des Diaphragma urogenitale in seine Endäste auf. Die Präparationen zeigten keinerlei direkte Verbindung des N. pudendus zur membranösen Harnröhre.

Entscheidend ist diese anatomische Darstellung für die Kontinenzerhaltung nach radikaler Prostatektomie und rekonstruktiver Chirurgie an der Harnblase, wie beispielsweise bei der Ersatzblasenbildung. Dabei ist die Schonung der membranösen Harnröhre von besonderer Bedeutung, weil damit auch die den distalen Bereich der Harnröhre versorgenden Nerven erhalten werden können. sorgen. Bei diesen Feten wurde zur Vorbereitung der weiteren Präparation das linke Os coxae, beginnend am Sakroiliakalgelenk unter Schonung der Beckeneingeweide und nachfolgender Durchtrennung der Symphyse, abgesetzt (Abb. 4).

Durch die mediane Inzision des M. bulbospongiosus konnte der Bulbus penis präpariert werden. Nach Durchtrennung des M. transversus perinei profundus wurde die membranöse Harnröhre dargestellt. Die Präparation der Nerven zur membranösen Harnröhre erfolgte mittels Lupenbrille, teilweise auch mit dem Präparationsmikroskop. Die Innervation der Pars membranacea urethrae erfolgt teils durch direkte Äste des Plexus pelvicus,

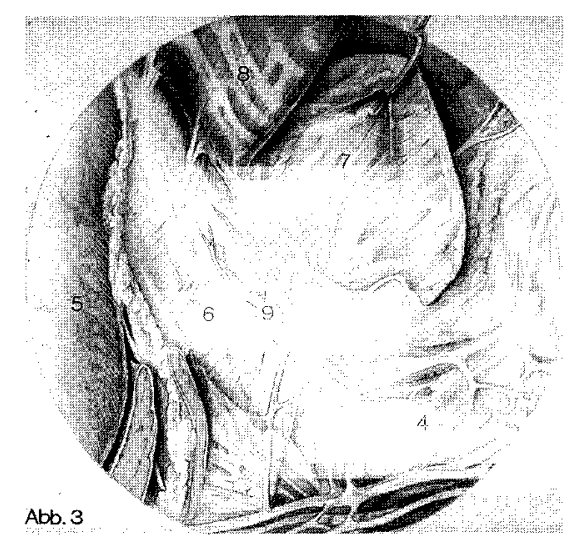

Abb. 6 Aquarell entsprechend zu Abb. 2

Abb. 6 1.Symphyse, 2. Harnblase, 3. Rektum, 4. Prostata, 5. Bulbus penis, 6. membranöse Harnröhre, 7. M. transversus perinei profundus, 8. M. bulbospongiosus, 9 . Nervenäste des Plexus pelvicus zur membranösen Harnröhre 
Schmitz-Dräger u. Mitarb. (Düsseldorf) berichtete über die mit dem Memorial Sloan-Kettering-Cancer-Center in New York durchgeführten „Untersuchungen zur Expression von Wachstumsfaktoren beim Nierenzellkarzinom": Neuere Untersuchungen weisen auf eine Korrelation zwischen der Expression von Wachstumsfaktoren (GF) und der malignen Transformation hin. GF sind auto- oder parakrin wirkende Polypeptide, die über eine Bindung an hochaffine Membranrezeptoren Wachstum und Differenzierung der Zielzelle beeinflussen. Eine veränderte Expression von TGF- $\alpha$, TGF- $\beta 1$ und FGF-like GF wurde für das Nierenzellkarzinom bislang beschrieben. Eine umfassende Charakterisierung der GF-Expression steht noch aus. In der vorliegenden Untersuchung wurden 5 Kurzzeitkulturen normaler Nierenzellen und 14 Nierenkarzinom-Zellinien auf die Expression von 10 verschiedenen GF hin untersucht. Um auch eine minimale Expression nachweisen zu können, erfolgte die Untersuchung mit Hilfe der DNA-Polymerase-Kettenreaktion (PCR).

Aus den RNA-Präparationen der verschiedenen Zellinien erstellte man durch reverse Transkription cDNA. Mit Hilfe spezifischer Primer wurden die entsprechenden Gen-Segmente mit der PCR über 35-50 Zyklen amplifiziert. Es wurden Primer für die GF TGF- $\alpha$, TGF- $\beta 1$, TGF- $\beta 2$, TGF- $\beta 3$, FGF-a, FGF-b, FGF- 5 , Hst-1, KGF, PDGF$\alpha$ und PDGF- $\beta$ verwendet. Die Identifizierung der amplifizierten Gensegmente erfolgte anhand der Fragmentgröße im 1\%-Agarose-Gel. Die Spezifität der Amplifikation wurde durch direkte Sequenzierung des amplifizierten Genes oder Verdauung mit Restriktionsenzymen überprüft.

Mit Ausnahme von Hst-1 wurden alle untersuchten GF von normalen Nierenzellen exprimiert. TGF- $\alpha$, TGF- $\beta 1$, TGF- $\beta 2$, FGF- $b$, PDGF- $\alpha$ und PDGF- $\beta$ wurden in allen untersuchten Nierenkarzinomzellinien nachgewiesen. TGF- $\beta 3$ war in $5 / 5$ Zellinien von Primärtumoren und in $7 / 9$ der Zellinien aus Fernmetastasen vorhanden. FGF-a wurde lediglich in 1/5 Zellinien von Primärtumoren und in 4/9 Zellinien aus Fernmetastasen beobachtet. FGF-5 und KGF waren in 2/5 und 3/5 der Zellinien von Primärtumoren und in 3/9 und 4/9 der Zellinien aus Fernmetastasen exprimiert. Hst-1 wurde in je 1 Zellinie aus dem Primärtumor und 1 Zellinie aus einer Fernmetastase nachgewiesen.

Diese Ergebnisse zeigen, daß der Verlust der Expression eines oder mehrerer GF beim Nierenzellkarzinom nicht ungewöhnlich ist, während eine Neuexpression ein eher seltenes Ereignis darstellt. Aufgrund dieser Ergebnisse könnten zum einen quantitative Veränderungen der GF-Expression, zum anderen aber auch ein qualitativ verändertes GF-Muster eine Transformierung oder das Metastasierungspotential der Zelle signalisieren. Eine dritte Möglichkeit der Regulation des Einflusses besteht in einer veränderten Expression der GF-Rezeptoren. Weitere Untersuchungen müssen sich daher verstärkt mit den quantitativen Aspekten der GF-Expression und Expression von GFRezeptoren beim Nierenzellkarzinom befassen.

In seinem Vortrag "Liposomen in Tumortherapie: Alte Versprechen und neue Aussichten" gingen $\mathrm{Cevc}$ u. Mitarb. auf den aktuellen Forschungsstand dieser Behandlungsmodalität ein. Lipidvesikel (Liposomen) wurden wiederholt als Wirkstoffträger diskutiert, beson- ders für die Behandlung von Krebs und Infektionen. Das ist einerseits die Folge der Tatsache, daß so gut wie jeder Wirkstoff in die Liposomen entweder in das wäßrige Vesikelinnere oder in die fettähnliche Lipiddoppelschicht eingeschlossen werden kann. Andererseits aber beeinflussen die Liposomen auch die Pharmakokinetik der eingeschlossenen Agentien; sie können mindestens prinzipiell die lokale Wirkstoffkonzentration erhöhen und die unerwünschten Nebenwirkungen verringern.

Es ist daher nicht verwunderlich, daß es bereits sehr viele Artikel über die - vermeintlichen und wirklichen - therapeutischen Vorzüge der Liposomen gibt; die agenstragenden Lipidvesikel wurden auch schon auf mehreren hundert Patienten eingesetzt. Nichtsdestotrotz bleiben jedoch viele der ursprünglichen Verheißungen über den klinischen Nutzen von Liposomen unerfüllt; ferner sind noch etliche technologische, aber auch therapeutische mit Liposomen zusammenhängende Fragen zu lösen. Das betrifft besonders das Problem der raschen Liposomeneliminierung aus dem Blut. Auch die Effizienz der verstärkten Trägeraufnahme im Tumorgewebe und in der Tumorumgebung ist in vielen Fällen noch fragwürdig.

Vor einiger Zeit berichteten Cevc u. Mitarb. über die erste Verwendung von fusionsfähigen Liposomen für die selektive Wirkstoffverabreichung. In einer Reihe von Versuchen konnte seitdem gezeigt werden, daß besonders solche Körperstellen, die auf eine Temperatur oberhalb von einer gewissen kritischen Temperatur erwärmt sind, hohe Dosen von Stoffen abbekommen, die in thermolabilen Liposomen verabreicht wurden. Aus praktischen Gründen wurde diese Temperatur zumeist auf $42-43^{\circ} \mathrm{C}$ festgelegt.

In neueren Tierexperimenten wurde jetzt festgestellt, daß die Dosis der Stoffe, die mit thermolabilen Liposomen der ersten Generation eingebracht wurden, im hyperthermierten Gewebe in der Regel um mindestens $50 \%$ höher ist als im normothermischen Körperbereich. Diese In-vitro-Experimente sprachen jedoch dafür, daß mit weiterentwickelten fusionsfähigen Liposomen noch um einen Faktor von 10 bessere Ergebnisse erzielbar sind.

Der Einsatz von Hyperthermie als externer Zeiger, der die Wirkstoffträger in das Zentrum der Erkrankung leitet, ist jedoch mit erheblichem technischen Aufwand und Erfahrungsnotwendigkeit verbunden. Daher wurde versucht, auch solche Liposomen zu entwickeln, die sehr lange in der Zirkulation bleiben und dabei die Stoffe, die sie enthalten, allmählich freigeben. Solche Liposomen (Kryptosomen) sollen die Schwelle für die therapeutische Wirkung herabsetzen oder die Grenze, bei der die Nebenwirkungen auftreten, erhöhen. Kryptosomen sollen des weiteren durch einen „Retard-effekt" auch für gleichmäßigere Wirkstoffspiegel im Blut sorgen. Nicht zuletzt soll die liposomale Langlebigkeit die Aussichten für eine Penetration der Vesikel in das Zielgewebe erhöhen.

Die entwickelten Kryptosomen entsprachen diesen Vorstellungen. Sie bestehen aus mittelgroßen, kompakten Vesikeln mit einer oder einigen wenigen Lipiddoppelschichten. Diese sind sterisch stabilisiert durch einen Zusatz von großköpfigen Phospholipiden. Die besten Ergebnisse wurden bisher mit Liposomen aus Distearoylphos- 
phatidylcholin (DSPC) erreicht, die 10\% von Distearoylphosphatidylethanolamin mit kovalent gebundenem Polyethyleneglycol 5000 als Kopfgruppenverlängerung enthalten. Solche Liposomen sind $8000 \%$ langlebiger als vergleichbare Vesikel aus reinem Distearoylphosphatidylcholin: nach 24 Stunden befanden sich noch über $25 \%$ von Kryptosomen und lediglich einige wenige Prozent von DSPC-Liposomen im Blut.

Die antineoplastische Substanz Carboplatin ließ sich zu ca. $40 \%$ in die Kryptosomen einschließen; in vivo werden davon pro Tag ungefähr $20 \%$ freigesetzt. Dies gewährleistete einen Wirkstoffspiegel, der die Charakteristika bisheriger Formulierungen bei weitem übertrifft. Kryptosomen der beschriebenen Art wurden auch, wie gewünscht, in einem signifikanten Ausmaß im Tumorgewebe angereichert. Der Grad der Anreicherung hing dabei von der Tumorgröße ab; relativ betrachtet ist er um so größer, desto kleiner die Tumoren sind.

Im Falle von oberflächlichen und/oder gut zugänglichen Tumoren ist es auch wünschenswert, die Diffusion (Permeation) von Wirkstoffen von der Verabreichungsstelle hin zum Tumorgewebe zu verstärken. Auch für solche Anwendungen wurde ein neuer Wirkstoffträger, sogenannte Transfersomen, entwickelt.

Die Transfersomen zeichneten sich durch folgende Spezialeigenschaften aus: a) sie spüren bei der Permeation durch Endothelien und Epithelien nur einen relativ geringen Widerstand und b) sie sind fähig und bestrebt, spontan in das Gewebe zu penetrieren. Die zweite Anforderung läßt sich am einfachsten im Falle von topischer, perkutaner Applikation verstehen und verwirklichen; hier ist die Dehydratation, die „liposomale Angst vor dem Austrocknen an der Hautoberfläche" die treibende Kraft für die Trägerpermeierung. (Bei einer intravesikalen Applikation wären z.B. hohe Konzentrationsgradienten oder externe Druckunterschiede [elektrischer, hydrostatischer, usw. Natur] als treibende Kräfte erforderlich.)

Es wurden analgetische Transfersomen als Modellsystem benutzt, um zu zeigen, daß mit solchen Trägern $100 \%$ der applizierten Substanz durch die menschliche oder tierische Haut eingebracht werden kann, vorausgesetzt, daß die Trägerzusammensetzung optimiert ist. Nach einer perkutanen Analgetikaapplikation mittels Transfersomen dauert es lediglich 5-10 Minuten, bis eine volle topische Analgesie eintritt. Diese dauerte ungefähr doppelt so lange wie im Falle von s. c. gespritztem Analgetikum vergleichbarer Konzentration.

Zusammenfassend wurde festgestellt, daß die Liposomen für eine topische Therapeutika-Applikation gut geeignet sind, wenn der abgegrenzte Auftragsort für die lokale Wirkung sorgt oder wenn durch externe Maßnahmen die Träger zu einem bestimmten Zielort im Körper geführt werden können. Ferner wurde gezeigt, daß Spezialliposomen Tage lang in der Blutzirkulation erhalten bleiben können und dort für eine allmähliche Wirkstoffreisetzung sorgen. Jeder dieser neuen Liposomentypen bietet mindestens einen potentiellen Gewinn für die Tumortherapie. Wie groß letzten Endes der daraus resultierende Nutzen für die onkologischen Patienten sein wird, wird erst der zukünftige klinische Einsatz zeigen.
Im Vortrag „Immunotargeting zur Therapie des Blasentumors - Entwicklung eines murinen Modells" führte Breul (München) aus, daß bei Versuchstieren durch Verfütterung mutagener Substanzen Harnblasenkarzinome erzeugt werden konnten. Diese Karzinomzellen lieBen sich in Zellkultur überführen. Die subkutane Injektion von Tumorzellen führte zu einem raschen Tumorwachstum an der Injektionsstelle. Durch Hyperimmunisierung mit letal bestrahlten, syngenen Tumorzellen stellte sich das Wachstum der Tumoren deutlich verlangsamt dar.

In den Seren der immunisierten Versuchstiere waren im ELISA hohe Antikörpertiter gegen Tumoroberflächenantigene nachweisbar. Es wurden verschiedene monoklonale Antikörper gegen tumorassoziierte Antigene nach der von Köhler und Milstein beschriebenen Methode hergestellt. 7 Klone, die Antikörper produzierten, die allein mit Tumorzellen, nicht aber mit normalem Blasengewebe reagierten, wurden isoliert. Die Antikörper wurden von Medienbestandteilen über eine Protein G-Säule gereinigt. Die gereinigten Antikörper werden an eine lipophile Substanz gekoppelt.

Die Antikörperkonjugate wurden mit fusionsfähigen, zytostatikabeladenen Liposomen inkubiert. Es entstanden so mit spezifischen Erkennungsstrukturen ausgestattete Liposomen, die als „drug carrier“-Systeme die Zytostatika direkt an die Tumorzellen transportieren und eine unmittelbare Fusion ermöglichen sollen (Abb. 7). Eine spezifische Tumortherapie wäre somit möglich. Der Effekt dieser spezifischen Antikörper beschichteten Liposomen wird zur Zeit in vitro und in vivo ausgetestet.

Kurth u. Mitarb. (Amsterdam) gingen auf die „Kinetik der Zytokine unter Immuntherapie mit BCG bei Blasentumoren Kategorie Tis, Ta und T1 " ein. Er leitete seinen Vortrag ein mit der Feststellung, daß sich die intravesikale Immuntherapie mit BCG (Bacillus Calmette-Guerin) zur Behandlung des Carcinoma in situ der Harnblase und zur Rezidivprophylaxe nach transurethraler Resektion oberflächlicher Blasentumoren der Kategorie Ta/T1 bewährt hat. Mögliche immunologische Wirkungsmechanismen, über die BCG seine spezifische, gegen den Tumor gerichtete Effektivität entwickelt, sind bisher ungeklärt.

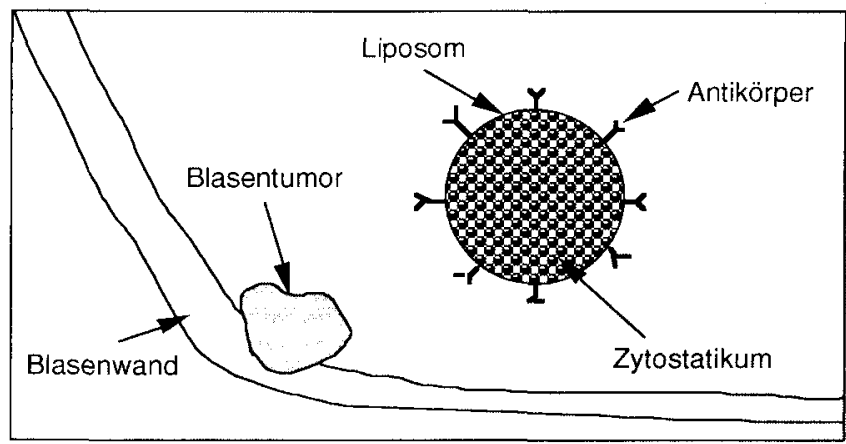

Schematische Darstellung der Wirkung von spezifischen, Antikörperbeschichteten, Zytostatika-beladenen Liposomen

Abb. 7 Liposom als „drug carrier"-System zum Transport zytostatischer Substanzen an die Tumorzelle mit der Möglichkeit der unmittelbaren Fusion 
In einer prospektiven Untersuchung wurden während 6 wöchentlichen Instillationen von BCG die Kinetik von Zytokinen im Harn sowie die Zellexkretion bei 7 Patienten untersucht (1 Pat. mit Tis, 6 Pat. mit Ta/T1). Die Titer der verschiedenen Zytokine wurden in Harnproben bestimmt, die vor BCG-Instillation, 2-3, 3-6, 6-12 und 12-24 Stunden nach Instillation gesammelt wurden (insgesamt 210 Proben). Die Bestimmung der Zellexkretion erfolgte aus Blasenspülpräparaten, die unmittelbar vor Instillation, 3 und 24 Stunden nach Instillation gewonnen wurden. Die Zytokine Interleukin-1- $\beta$ (IL-2 $\beta$ ), Tumor-NecrosisFaktor-Alpha (TNF $\alpha$ ), „Granulocyte-Macrophage-colonystimulating factor" (GM-CSF) wurden mit einem IRMA-System bestimmt (Detektionsgrenze DL $5 \mathrm{pg} / \mathrm{ml}$ ), Interferongamma und Interferon-beta (IFN- $\gamma$, IFN- $\beta$ ) wurden mit einem IRMA oder ELISA bestimmt (DL 1U/ml), IL-2 wurde gemessen mit einem RIA (DL: 0,5 ng/ml) und einem Bioassay nach Dialyse (DL $30 \mathrm{pg} / \mathrm{ml}$ ). IL-6 wurde mit einem ELISA und einem Bioassay (nach Filtration) bestimmt (DL 5 $\mathrm{pg} / \mathrm{ml}$ ). Die Meßergebnisse wurden ausgedrückt bezogen auf die Konzentration von Kreatinin $\mu \mathrm{mol} / \mathrm{ml}$ im Harn.

Alle prophylaktisch mit BCG behandelten 6 Patienten mit den Tumorstadien $\mathrm{Ta} / \mathrm{T} 1$ zeigten innerhalb von 3-6 Monaten ein Tumorrezidiv, der Patient mit Tis G3 reagierte mit einer kompletten Remission zytologisch und bioptisch (12 + Monate).

Spitzenwerte für IL-2 und IL-6 fanden sich 2-6 Stunden nach Instillation. Die Ergebnisse waren unabhängig von der Bestimmungsmethode mit RIA, ELISA oder Bioassay. Hingegen fanden sich keine erhöhten Werte für

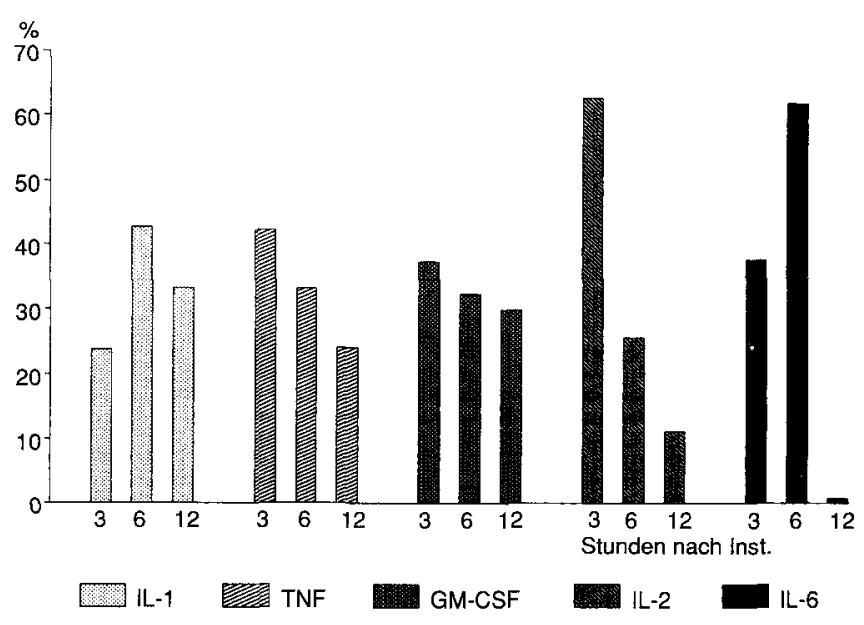

Abb. 8 Nach jeder BCG-Instillation wurde für jeden Patienten der Spitzenwert in Abhängigkeit vom Intervall zur instillation ermittelt $(2-3,3-6$ und $6-12 \mathrm{~h}$ nach Instillation, 210 Messungen in triplo ausgeführt). Nach insgesamt 42 Installationen ( 6 Installationen für 7 Pat.) zeigt sich ein unterschiedliches Bild für die verschiedenen Zytokine sowie unterschiedliche Spitzenwerte in Abhängigkeit von der Sammeiperiode. Hieraus ergibt sich die Notwendigkeit, bei der Untersuchung der Kinetik verschiedener Zytokine, die Proben zu unterschiedlichen Zeitpunkten nach der Installation zu sammeln, um den Zeitpunkt der Spitzenwer. te zu definieren.
IL-1, TNF und GM-CSF in Abhängigkeit vom InstillationsIntervall. IFN- $\beta$ und IFN- $\gamma$ waren nach BCG-Installation nicht meßbar (Abb. 8).

Trotz einer deutlich individuellen Varianz der Kinetik von IL-1- $\beta$, TNF $\alpha$ und GM-CSF zeigten auf BCG nicht-respondierende Patienten einen leichten Anstieg dieser Zytokine nach BCG-Instillation. IL-6 stieg stärker an und blieb während der gesamten Dauer der Instillationsbehandlung auf einem erhöhten Wert. Für IL-2 wurde kein Anstieg bei nicht-respondierenden Patienten gefunden. Alle Zytokine zeigten beim respondierenden Patienten einen deutlich höheren Anstieg. Er betrug für IL-2 das 5 fache und für IL-6 das 30 fache des Wertes nicht-respondierender Patienten. Aus dem Unterschied der Ergebnisse für nicht-respondierende und dem respondierenden Patienten kann man den Therapieerfolg feststellen. Die beobachteten IL-2-Erhöhungen in Abhängigkeit vom Behandlungsresultat stimmen mit Mitteilungen in der Literatur überein.

Eine detaillierte Analyse der IL-6-Kinetik mit Einschluß aller Patienten unabhängig vom Behandlungsresultat zeigte, da $\beta$ die Patienten in 2 Gruppen unterteilt werden können, nämlich die mit deutlichem IL-6 Anstieg und jene ohne Anstieg von IL-6 (Abb. 9). Interessanterweise war die IL-6 Kinetik deutlich mit dem Zellanstieg (hauptsächlich Granulozyten), ermittelt aus den Blasenspülpräparaten, korreliert $(\mathrm{r}=0,915)$.

Die vorgelegten Ergebnisse, insbesondere der Nachweis oder das Fehlen einer entzündlichen Reaktion (ablesbar am IL-6 Anstieg und der veränderten Granu-

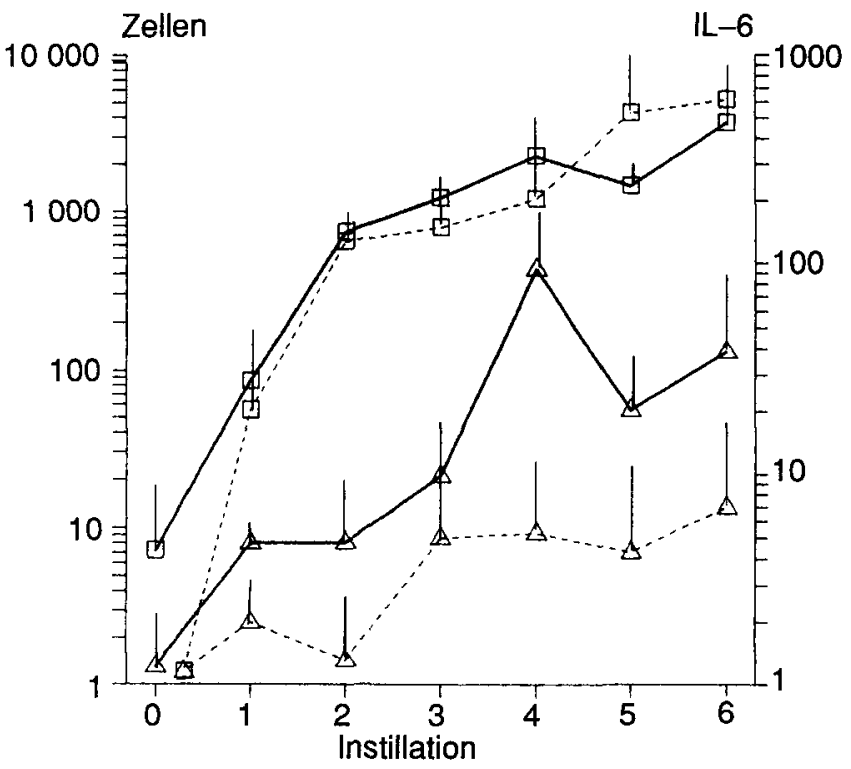

Abb. 9 Die Kurven zeigten gemittelte wöchentliche Spitzenwerte für IL-6 (. .) und der Zellexkretion (-), ermittelt aus den Blasenspülproben $3 \mathrm{~h}$ nach installation. Hohe Werte für IL-6 korrelieren mit einer erhöhten Zellexkretion (4 Pat.) [und vice versa geringer IL-6 Anstieg mit einer geringeren Zellexkretion (3 Pat.) [ם]. (IL-6 in pg/ $\mu$ mol Kreatinin, Zellanzahl/ml Blasenspülvolumen) 
lozytenexkretion bei klinisch nichtrespondierenden Patienten), scheinen eine BCG-assoziierte Antitumor-Aktivität auf Basis einer rein entzündlichen Reaktion auszuschließen. Vielmehr kann an eine Assoziation zwischen BCG-induzierter Antitumor-Aktivität und einer „delayed type hypersensitivity reaction" mit oder ohne entzündlicher Reaktion gedacht werden. Weitere Untersuchungen sind darauf gerichtet, an einer größeren Anzahl von Patienten den prognostischen Wert der Zytokin-Kinetik zu ermitteln.

Jocham (Lübeck) stellte die „Tumorfrüherkennung mit Hilfe der photodynamischen Laserfluoroszenzdetektion " vor. Tumorareale, die histologisch z. B. einer schweren Atypie oder einem Carcinoma in situ der Blase entsprechen, sind endoskopisch häufig nicht zufriedenstellend diagnostizierbar. Solche Tumorherde weisen eine vermehrte Speicherung des systemisch verabreichten Fluoreszenztumormarkers Photofrin $I^{\circledR}$ auf, der im Rahmen der photodynamischen Lasertherapie auch therapeutisch eingesetzt wird.

Für diagnostische Anwendungen ist eine Absenkung der Substanzdosis zur Vermeidung einer systemischen Photosensibilisierung sinnvoll. Diagnostisch verwertbare Fluoreszenzsignale können auch noch bei Verabreichung von einem Zehntel der therapeutischen Dosis ( $2 \mathrm{mg} / \mathrm{kg} \mathrm{KG}$ ) induziert werden. Bei dieser niedrigen Markerdosierung können der Tumorfluoreszenz störende Autofluoreszenzsignale überlagert sein, die eine tumorspezifische Zuordnung der Fluoreszenz erschweren.

Seit 1984 wurde ein Fluoreszenzdiagnosesystem entwickelt, das rechnergestützt die über eine zweite Anregungswellenlänge induzierte Autofluoreszenz gegenüber der Gesamtfluoreszenz (Photofrin II ${ }^{\circledR}$-Fluoreszenz+ Autofluoreszenz) substrahieren läßt. In das Diagnosesystem sind ein modifizierter Krypton-Ionen-Laser, der zwei Wellenlängen ( $405 \mathrm{~nm}$ und $480 \mathrm{~nm})$ emittieren läßt, ein optischer Vielkanalanalysator (OMA), eine speziell entwikkelte Bildverarbeitung sowie ein modifiziertes Endoskop und ein Lichtverstärkungssystem (Image-Intensifier) integriert).

Experimentelle $(n=47)$ sowie klinische $(\mathrm{n}=17)$ Untersuchungen an tumortragenden Blasen (Fluoreszenzsignal in Korrelation zur Biopsie) zeigten, daß die Rate der klinisch besonders relevanten falsch-negativen Befunde mit $2 \%$ sehr niedrig ist. Falsch-positive Befunde (28\%) sind durch Speicherung des Fluoreszenzmarkers in entzündlichem Gewebe bedingt. Derzeit läuft die weitere Systemoptimierung sowie die klinische Validierung mit Einsatz des Verfahrens auch in anderen Organsystemen.

Im Vortrag „Erhöhte TGF- $\beta 1$ mRNA sind mit ras+myc-induzierten Karzinomen der rekonstituierten Maus-Prostata verbunden: Evidenz einer parakrinen Rolle während Progression" befaßten sich Merz u. Mitarb. (Bern) mit der Bedeutung von TGF- $\beta 1$ in der Genese von ras + myc - induzierten Karzinomen.

In den letzten Jahren wurde festgestellt, daß sich ein Karzinom etappenweise entwickelt. Jede Etappe bedeutet eine Änderung auf der Ebene des zellulären Genoms. Es gibt verschiedene Arten von genetischen Ände- rungen wie Gen-Amplifikation, Translokation und Gen-Mutation (z. B. Aktivierung eines Proto-Onkogens). Um die Progression des Prostatakarzinoms zu untersuchen, wurden Zellen aus dem urogenitalen Sinus (UGS) eines Mäusefetus (C57 BL6) mit Helperfree rekombinaten Retroviren, die zwei kooperative Onkogene (ras + myc) enthielten, inkubiert. Das UGS wurde dann unter die renale Kapsel einer isogenen männlichen Maus transplantiert. Wenn diese konstruierten Retroviren sowohl mit epithelialen und mesenchymalen Anteilen des UGS inkubiert wurden, entwickelten sich ausschließlich undifferenzierte Adenokarzinome der Prostata. Die Infektion lediglich des epithelialen oder mesenchymalen Anteils mit konstruierten Retroviren führte nach Inkubation entweder mit normalem mesenchymalen bzw. epithelialen UGS-Gewebe in 15/17 Fällen zu einer epithelialen Hyperplasie oder bei 15/15 Fällen zu einer mesenchymalen Dysplasie. In 2/17 Fällen mit selektiv transformiertem Epithel wurden Karzinome beobachtet. $\mathrm{Ob}$ dies ein Hinweis ist, daß die epitheliale Hyperplasie in gewissen Fällen einem prämalignen Stadium entspricht oder ob andere Ursachen die maligne Transformation verursacht haben, ist nicht bekannt.

Die Expression von mRNA-Werten, welche für die Synthese des TGF- $\beta 1$ verantwortlich sind, war in allen onkogeninduzierten Karzinomen erhöht. In normalem UGS-Gewebe und in den Zellen mit epithelialer Hyperplasie waren die mRNA für TGF- $\beta 1$ nicht nachweisbar. Erhöhte mRNA-Werte von TGF- $\beta 1$ wurden auch in den mesenchymalen Dysplasien gefunden. Dies deutet möglicherweise auf eine potentielle parakrine Aktivität des ras+myc enthaltenden transformierten Mesenchyms. Es ist nicht ausgeschlossen, daß TGF- $\beta 1$ eine wichtige Rolle in der Genese von ras + myc-induzierten Karzinomen spielen könnte.

Der Höhepunkt der Veranstaltung war die Verleihung des C. E. Alken-Preises 1990 an R. J. A. Van Moorselaar aus Nijmegen. Mit diesem Preis wurde die Arbeit ,Interferon und Tumor-Nekrose-Faktor in der Therapie des Nierenzellkarzinoms: Erkenntnisse bisheriger experimenteller Studien " prämiert. In seinem Festvortrag berichtete van Moorselaar, daß die Behandlung des fortgeschrittenen Nierenzellkarzinoms durch geringe Ansprechraten gegenüber chemotherapeutischen und hormonellen Substanzen gekennzeichnet ist. Alternative Therapieformen - wie z.B. die Immuntherapie - sind deshalb z.Z. Gegenstand intensiver Untersuchungen. Zur endgültigen Beurteilung neuer Therapieformen sind kontrollierte, randomisierte Studien erforderlich. Die Schwierigkeiten dieser Untersuchungen zur Evaluation therapeutischer Parameter bei Patienten sind in den Kosten, dem beträchtlichen Zeitaufwand sowie nicht zuletzt häufig in ethischen Problemen zu sehen. Tiermodelle, die als repräsentative biologische Systeme für humane Karzinome dienen können, haben sich zur Beurteilung neuer therapeutischer Ansätze bewährt.

Um die direkten und indirekten antiproliferativen Effekte von Ratten-Gamma-Interferon (IFN) und Tumor-Nekrose-Faktor (TNF) beim Nierenzellkarzinom (NZK) abschätzen zu können, wurden In-vitro- und In-vivo-Studien in einem Rattennierenkarzinommodell durchgeführt. Es handelt sich um ein spontan entwickeltes NZK bei einer männlichen Wistar-Lewis-Ratte, das durch Transplantatio- 
nen über vielfache Passagen erhalten werden konnte. Histologisch findet sich ein hellzelliges NZK, bei welchem sich elektronenmikroskopisch Desmosomen darstellen lassen. Studien zur Expression intermediärer Filamente zeigten wie bei den meisten humanen NZK eine Koexpression von Vimentin und Zytokeratinen. Flowzytometrisch ließ sich ein aneuploider DNA-Index nachweisen.

Um Einsicht in die direkten inhibitorischen Effekte von Zytokinen auf die proliferative Aktivität der Zellen eines NZK zu gewinnen, wurden In-vitro-Experimente mit einer Zellinie durchgeführt, die vom beschriebenen Tumor abstammte. Die In-vitro-Verdopplungszeit dieser Zellinie beträgt 28 Stunden. Die histomorphologischen Charakteristika entsprachen denen des Originaltumors. Zusätzlich bildet diese Zellinie In-vitro-Sphäroide und erwies sich als tumorbildend in Lewis-Ratten. In-vitro-Experimente wurden mit Einzelzellsuspensionen durchgeführt. Dabei wurden die Tumorzellen in die obere Schicht eines zweischichtigen Softagar-Systems gebracht. Die Zytokinapplikation erfolgte als einmalige Gabe am ersten Tag nach Beschickung des Softagars mit Tumorzellen. Die Tumorzellkoloniebildung wurde über drei Wochen verfolgt und mit einem Omnicon Fas II-Counter quantifiziert. Eine dosisabhängige Inhibition der Koloniebildung bei Anwendung einer ZytokinMonotherapie war ersichtlich. Die Kombination von $100 \mathrm{ng}$ TNF und 10 oder 100 U IFN zeigten sogar synergistische Effekte.

Weitere In-vitro-Studien wurden mit multizellulären Tumorsphäroiden (MTS) durchgeführt. Dabei handelt es sich um ein In-vitro-Modell, das in seiner Komplexität zwischen Tumoren in vivo und den herkömmlichen In-vitro-Modellen - wie z. B. Zellsuspensionen oder Monolayerkulturen - liegt. MTS repräsentieren avaskuläre Tumoren oder Metastasen mit fast kugeliger Form. Dabei kann man eine äußere Zellschicht aus sich teilenden Zellen von einer Zwischenschicht unterscheiden, die aus ruhenden Zellen besteht. In Abhängigkeit vom Sphäroidtyp entwickelte sich ab einem bestimmten Durchmesser eine zentrale Nekrose. MTS mit $250 \mu \mathrm{m}$ Durchmesser wurden mit steigenden Dosen IFN und TNF inkubiert (250-1000 UI oder ng/ml Kulturmedium). Das Medium wurde zweimal wöchentlich erneuert. Die IFN-Monotherapie zeigte keine Wachstumshemmung. Auch die Steigerung der IFN-Gabe von zwei- auf fünfmal pro Woche zeigte keine antiproliferativen Effekte. Dagegen fand sich bei einer TNF-Monotherapie dosisabhängig eine antiproliferative Wirkung. In Kombination konnte IFN die Wirkung von TNF nicht steigern. Die Kombination von TNF und externer Bestrahlung mit 4 oder 6 Gy zeigte hingegen additive oder synergistische Effekte.

Ergebnisse dieser In-vitro-Studien lassen jedoch nur begrenzt Rückschlüsse für die klinische Anwendung zu, da die wechselseitigen Beeinflussungen von Zytokinen und Immunsystem des Empfängers nicht erfaßt werden können. Entsprechend wurden In-vivo-Studien durchgeführt, bei denen das NZK Ratten subkutan transplantiert wurde. Die Applikation der Zytokine erfolgte peritumoral, wobei IFN dreimal und TNF fünfmal wöchentlich gegeben wurde. Die IFN-Behandlung begann 2 Tage nach Tumorimplantation und zeigte einen dosisabhängigen antiproliferativen Effekt. Bei TNF fand sich dagegen nur in der höchsten
Konzentration eine wachstumshemmende Wirkung. Unterschiedliche Kombinationen beider Zytokine ergaben additive oder synergistische antiproliferative Effekte. Die Kombination der jeweils höchsten Dosierungen mit 80000 U IFN und $100 \mu \mathrm{g}$ TNF pro Ratte resultierte in einer kompletten Wachstumsunterdrückung. Der antitumorale Effekt war abhängig vom Tumorvolumen zu Therapiebeginn. Die Monotherapie versagte bei etablierten Tumoren. Die Kombination der jeweiligen Höchstdosierungen (s. o.) stabilisierte das Tumorvolumen, selbst wenn dies zwischen 2 und $5 \mathrm{~cm}^{3}$ zu Therapiebeginn betrug.

Van Moorselaar schlußfolgerte, daß die Kombination von IFN und TNF als potentes therapeutisches Regime in der Behandlung des NZK angesehen werden kann. Die besten Ergebnisse werden beobachtet, wenn das Tumorvolumen so gering wie möglich ist. Die durchgeführten Studien weisen deshalb darauf hin, daß Patienten mit einem NZK von einer Immuntherapie den größten therapeutischen Effekt erwarten können, wenn die Therapie so früh wie möglich beginnt, d.h. im Stadium der lokalen Erkrankung, unmittelbar nach der Nephrektomie. Die Nebenwirkungen der Zytokintherapie machen jedoch eine Selektion der Patienten notwendig, die ein besonders hohes Risiko einer möglichen Progression zeigen. Das Fehlen von Risikokriterien für eine solche Immuntherapie erschwert z.Z. die Durchführung entsprechender Studien.

Die Kombination von Chemo- und Immuntherapie erscheint vielversprechend. Eine potentiell wirksame Kombination könnte die gemeinsame Applikation von TNF und Chemotherapeutika darstellen, deren Angriffspunkt die DNA-Topoisomerase II ist. Hierzu gehören Adriamycin, Actinomycin und Etoposid (VP 16). Die Gabe von VP 16 und TNF nach Nephrektomie zeigte einen signifikanten Rückgang der Lokalrezidive in NZK-Xenograft-Studien. In keinem Fall konnten Metastasen nachgewiesen werden. Die Arbeitsgruppe untersuchte einen anderen DNA-Topoisomerase II-Inhibitor (Adriamycin) in Kombination mit TNF, sowohl in vitro als auch in vivo. TNF (1-1000 ng/Platte) und Adriamycin (2-20 000 ng/Platte) zeigten dosisabhängige antiproliferative Effekte in vitro, die in unterschiedlichen Kombinationen synergistisch waren. In den in vivo-Studien wurde Adriamycin intraperitoneal appliziert $(0,1$ oder $1 \mathrm{mg} / \mathrm{kg} \mathrm{KG})$. Die höchste Dosierung in der Adriamycin-Monotherapie, $1 \mathrm{mg} / \mathrm{kg} \mathrm{KG}$ an drei aufeinanderfolgenden Tagen in zweiwöchigen Abständen, zeigte signifikante antitumorale Effekte. Niedrigere Dosierungen ließen keine signifikanten wachstumshemmenden Wirkungen erkennen. Bei TNF-Kombinationstherapie fanden sich nur in Kombination mit höchster Adriamycindosis synergistische antiproliferative Effekte. Die Kombinationen waren jedoch signifikant effektiver als die entsprechende Monotherapie. Auch bei diesen Chemo-Immuntherapie-Kombinationen zeigte sich, daß bei großen Tumorvolumina zu Therapiebeginn keine signifikanten antitumoralen Effekte zu erzielen sind. Vergleichbare, bescheidene synergistische Effekte konnten mit der Kombination von TNF und VP 16 erzielt werden.

Zukünftige Studien sind erforderlich, um die Mechanismen der Zytokinwirkungen zu erklären, z.B. durch Analyse von Lymphozyteninfiltraten und HLA-Expression vor und nach Zytokintherapie. Weitere Studien 
werden außerdem die therapeutische Wirkung von monoklonalen Antikörpern und Zytokinen zum Gegenstand haben.

Jonas u. Mitarb. (Hannover) berichteten über „Proliferation und Ploidie als prognostische Faktoren beim Nierenzellkarzinom". Einige Zentren modifizieren die Standardtherapie der radikalen Tumornephrektomie beim Nierenzellkarzinom. So werden bereits elektiv Patienten mit einem kleinen, solitären Nierentumor organerhaltend (Tumorenukleation, Tumorresektion bzw. Polamputation) behandelt. Das Follow-up der Patienten mit einem organerhaltenden Therapieregime ist bei einer allerdings noch relativ kurzen Verlaufsbeobachtung vielversprechend, da über einen hohen Prozentsatz an tumorfreien Patienten berichtet wird.

Der Vorteil organerhaltender Eingriffe liegt in der Erhaltung der Nierenfunktion. Für Patienten mit einer normalen kontralateralen Niere ist dies jedoch von untergeordneter Bedeutung, da in der Regel der Verlust einer Niere keinen Einfluß auf die Gesamtclearance, Blutdruckregulation, Stimulation des hämatopoetischen Systems etc. hat. Dagegen ist die Radikalität aus onko-chirurgischer Sicht zweifelhaft, da synchron auftretende Tumorzellnester durch präoperatives Staging und intraoperative Inspektion nicht ausgeschlossen werden können. So z. B. untersuchten Lacour et al. 100 tumortragende Nieren, bei denen zuvor in CT, Angiographie bzw. Sonogramm kein Hinweis auf Satelittumoren bestand, also Tumoren, die sich nach den Kriterien vieler Zentren für ein organsparendes Vorgehen eignen würden. In 10\% der Fälle konnten bei normaler histopathologischer Aufarbeitung synchrone Tumorzellnester festgestellt werden. Im Einklang mit den Ergebnissen von Lacour stehen die Beobachtungen, daß ein Rezidiv nicht nur in der Resektionsfläche, vor allem jedoch im zuvor normalen, tumorfernen Nierengewebe auftreten kann. Aus dieser Erkenntnis ergab sich die Fragestellung, inwieweit in peritumoralem Normalgewebe Mikroherde von abnormalen Zellen (Tumorzellen) vorhanden sind. Mit Hilfe histologischer, zytophotometrischer und immunzytochemischer Methoden sollte das peritumorale Gewebe auf das Vorhandensein einzelner pathologischer Zellen hin untersucht werden.

In die Studie wurden alle Patienten mit einem solitären, organbeschränkten Nierenzellkarzinom (Stadium $\mathrm{T}_{1}$ bis $\mathrm{T}_{3}$ ) aufgenommen. Von bisher 38 tumornephrektomierten Nieren erfolgte die Gewebeentnahme vom Tumor und peritumoral gelegenen „Normalnieren“-Anteil. Es wurden für die DNS-Einzellzytophotometrie Abtupfpräparate und für die Immunzytochemie Gefrierschnitte $(5 \mu \mathrm{m})$ angefertigt. Nach Feulgen-DNS-Färbung konnte die DNS-Verteilung (Ploidie), die Proliferationsrate und der Anteil an Zellen mit pathologischem DNS-Gehalt ( $>5 \mathrm{C}$ ) automatisiert mit einem interaktiven Bildanalysesystem (MIAC ${ }^{\circledR}$, Fa. Leitz) bestimmt werden. Da im Gegensatz zur Flowzytometrie die Bildanalyse nicht nur die Möglichkeit der Ploidie-Bestimmung, sondern auch die zuverlässige Selektion sehr seltener Zellen und eine optische Kontrolle ermöglicht, wurde die Bildanalyse der Durchflußzytometrie vorgezogen. Immunzytochemisch wurde das Material auf Tumorantigenität hin untersucht. Mit Hilfe des nierenzellkarzinomspezifischen monoklonalen Antikörpers G 250 können einzelne Tumorzellen identifiziert werden. Mab G 250 ist ein Immunglobulin, welches spezifisch ( $>90 \%$ aller RCC, $>63 \%$ aller RCC-Metastasen) mit NZKAntigenen (Zellmembranantigen) eine Immunbindung eingeht. Dieses Antigen ist nicht auf der Zelloberfläche des normalen proximalen Tubulusepithels vorhanden.

Von den 38 Patienten zeigten 21 (55\%) der Tumoren eine diploide Verteilung. 17 (45\%) waren aneuploid. Das tumorfreie peritumorale Normalgewebe war bis auf eine Ausnahme diploid. In einem Fall konnte die triploide Tumorstammlinie im Normalgewebe nachgewiesen werden. Das Tumorgewebe zeigte eine Proliferationsrate zwischen $3-76 \%$, das peritumorale Normalgewebe zwischen $0,7-18 \% .22(58 \%)$ der Tumornieren hatten vereinzelt im peritumoralen Normalgewebe Zellen mit einem pathologisch erhöhten DNS-Gehalt (> 5C).

Immunhistochemisch konnte bei $25(66 \%)$ der peritumoralen Normalnieren ebenfalls vereinzelt Zellen mit RCC-spezifischer Tumorantigenität nachgewiesen werden. Hierbei zeigte sich, daß in G 250-positiven „Normalnieren" auch stark aneuploide Zellen festgestellt werden konnten. Die Immunhistochemie erwies sich jedoch als empfindlicherer Parameter bei der Suche nach abnormalen Zellen: Der Nachweis von pathologischen Zellen im peritumoralen Normalnierengewebe korrelierte nach bisherigen Auswertungen nicht mit dem T-Stadium. Andeutungsweise zeigt sich jedoch eine (statistisch bisher nicht signifikante) Tendenz, wobei gut differenzierte Tumoren peritumoral keine Zellen mit pathologischem DNS-Gehalt aufwiesen (Grad 1). Schlecht differenzierte Tumoren (Grad 3) zeigten eine erhöhte Rate an Aneuploidie. Grad 2-Tumoren waren im peritumoralen Normalgewebe heterogen.

Als Kontrollgruppe wurden Nieren untersucht, die aus nicht-onkologischen Gründen entfernt wurden. Sie zeigten keine G 250-Tumorantigenität. Die Ploidie war diploid, und im allgemeinen wurden keine Zellen mit einem pathologischen DNS-Gehalt gefunden. Jonas kam zu der Schlußfolgerung, daß sowohl die DNS-Analyse (Ploidie, aneuploide Zellen) als auch die Immunhistochemie darauf hinweisen, daß sich im ansonsten histopathologisch normalen, peritumoralen Gewebeanteil vereinzelt pathologische Zellen nachweisen lassen. Aufgrund der positiven Immunhistochemie ist es sehr wahrscheinlich, daß es sich um ruhende Tumorzellen handelt. Zur Zeit können noch keine konkreten klinischen Konsequenzen aus diesen Daten gezogen werden. Die klinische Relevanz dieser abnormalen Zellen wird durch subtiles Follow-up der Patientendaten überprüft.

Die Tatsache, daß organerhaltend behandelte Patienten in den ersten Jahren der Verlaufsbeobachtung keine Rezidive zeigten, spricht nicht gegen das Vorhandensein latenter Tumorzellen. Sämtliche bildgebende Verfahren sind nicht imstande, wenige pathologische Zellen in vivo zu diagnostizieren.

Leyh (München) stellte „Ploidie-Muster bei der benignen Prostatahyperplasie" vor. Durchflußzytometrische Untersuchungen stellen heute einen wesentlichen und bald unverzichtbaren Bestandteil in der Diagnostik onkologischer Erkrankungen dar. Die Veränderungen 
des zellulären DNS-Gehalts von diploiden zu hyperdiploiden und aneuploiden Erscheinungsformen sind eng verknüpft mit dem Auftreten maligner Zellveränderungen und korrelieren hierbei wiederum häufig mit dem Differenzierungsgrad der bösartigen Tumorerkrankung.

Ähnlich wie bei anderen urologischen Tumoren erlangt auch die Analyse des Ploidieverhaltens von Prostatakarzinomzellen zunehmende Bedeutung für prognoseorientierte Therapieentscheidungen. Darüber hinaus gehen Veränderungen der DNS-Histogramme in die Beurteilung von Therapieerfolg und -mißerfolg ein. Der Wert der DNS-Analyse für die Entdeckung des Prostatakarzinoms und die Überprüfung des Behandlungsverlaufes hängt jedoch in erster Linie davon ab, ausreichende Unterschiede in den DNS-Histogrammstrukturen zwischen benignen und malignen Zellen zu erkennen. Als erstes war daher zu klären, ob sich eine Aneuploidie in histologisch normalem Prostatagewebe findet. Sollte dies der Fall sein, wie ist dann der Stellenwert derartiger pathologischer Ploidiemuster in BPH-Proben einzuordnen? Des weiteren sollte überprüft werden, ob eine Erfassung histologisch noch nicht verifizierbarer prämaligner Zellveränderungen der Prostata bzw. der frühzeitigere Nachweis eines inzidentellen Karzinoms mit Hilfe der Durchflußzytometrie möglich ist.

Im Rahmen einer prospektiven Studie wurden hierzu mindestens 3 repräsentative Gewebeproben aus transurethralen Resektionsmaterialien von Patienten mit histologisch gesichertem Prostatakarzinom $(n=28)$ und Prostataadenom ( $n=54)$ durchflußzytometrisch untersucht.

Allen Zellproben wurden nach Gefriertrocknung und entsprechender Weiterverarbeitung zu einer gleichmäßigen Zellsuspension mit mehreren Zentrifugations- und Filtrierschritten mit dem DNS-Farbstoff Propidium Jodid angefärbt. Die durchflußzytometrische Zellanalyse erfolgte mit einem FACScan der Fa. Becton Dickinson. Aus jeder Probe wurden mindestens 5000 Zellen analysiert.

Bei einer Einstufung maligner Zellveränderungen alleine auf der Basis von aneuploiden Zusatzgipfeln oder eines überhöhten tetraploiden Gipfels konnten $43 \%$ der Prostatakarzinomproben als eindeutig aneuploid und dementsprechend $57 \%$ als diploid identifiziert werden. Unter den Proben von Patienten mit benigner Prostatahyperplasie waren nach dieser Klassifikation alle, also $100 \%$, diploid. Kennzeichnet man jedoch, wie von mehreren Untersuchern vorgenommen, auch eine Hyperploidie, ausgedrückt durch eine erhöhte Zellproliferationsrate (S + G2/MPase des Zellzyklus) von mehr als $20 \%$ als aneuploid, so erhöht sich der Prozentsatz der aneuploid eingestuften Prostatakarzinome auf $50 \%$.

Auffallend ist, daß auf der Basis einer erhöhten Proliferationsrate nun auch $4 \%$ der Prostataadenome als malignitätsverdächtig gewertet werden mußten. Diese Zahlen, die eine international einheitliche Definition des Aneuploidiebegriffes dringend notwendig machen, decken sich mit den Ergebnissen der Arbeitsgruppen um de Vere White in Sacramento (1989) und Tribukait in Stockholm (1987), die eine Aneuplodierate von 7 bzw. $8 \%$ für die BPH fanden.
Nicht berücksichtigt bei diesen $4 \%$ waren 6 Proben von Patienten mit einer BPH und 3 Karzinomproben, die zwar auch eine erhöhte Proliferationsrate von über $20 \%$ aufwiesen, die jedoch aufgrund einer überhöhten Schulter des G0/G1-Gipfels als entzündliche diploide Proben, und nicht als karzinomsuspekt eingestuft werden mußten. Im Unterschied zu den malignen Proben wiesen die entzündlichen Proben neben dem typischen „inflammatory tail“ innerhalb einer vergrößerten S-Phasen-Fraktion eine normale, nicht-überhöhte G2/M-Phase auf.

Eine Aufschlüsselung der einzelnen Zellzyklusphasen für die benignen und malignen Proben zeigte im Vergleich zu den gutartigen Zellproben bei den Prostatakarzinomen doppelt so hohe Prozentsätze für die G2/MPhase $(5,8 \%$ zu $12,8 \%)$. Unterteilte man nun die Prostataadenom- und Prostatakarzinomproben weiter nach diploiden und aneuploiden Präparaten, so mußten die aneuploiden, histologisch jedoch gutartig eingestuften Zellproben mit einer G2/M-Zellfraktion von $13 \%$ zwischen diploiden und den aneuploiden Karzinomproben mit einer Zellverteilung in der G2/M-Phase von 6 bzw. 20\% eingereiht werden.

Die retrospektive Überprüfung der 2 suspekten Adenomproben zeigte, da $B$ in einem Fall ein als dringend suspekt einzustufender PSA-Wert von $20 \mathrm{ng} / \mathrm{ml}$ eventuell doch auf das Vorliegen eines bislang histologisch nicht-erfaßten Prostatakarzinoms hindeutete.

Leyh schlußfolgerte, daß die Frage, ob es eine Aneuploidie bei der BPH gibt, derzeit noch nicht schlüssig beantwortet werden kann. Vorliegende Untersuchungen, deren Reproduzierbarkeit an einem größeren Krankengut derzeit überprüft wird, sowie ähnliche Berichte in der Literatur haben jedoch gezeigt, daß aneuploide DNSVerteilungen bei histologisch zum jeweiligen Untersuchungszeitpunkt als benigne eingestuften Prostatgeweben nachzuweisen sind. Inwieweit diese histologisch eventuell noch nicht verifizierbare oder verifizierte maligne Zellveränderungen darstellen, kann erst durch Langzeitbeobachtungen geklärt werden.

Um den Stellenwert der durchflußzytometrischen DNS-Analyse für die Frühdiagnostik des Prostatakarzinoms weiter abzuklären, muß man deshalb bereits jetzt empfehlen, im Rahmen prospektiver Studien nicht nur Gewebeproben bei nachgewiesenem Prostatakarzinom, sondern bereits einen Teil des Prostatabiopsiematerials neben der histologischen Abklärung auch durchflußzytometrisch zu untersuchen. Darüber hinaus sollten Patienten mit einer aneuploiden Histogrammstruktur bei histologisch normalem Prostatagewebe neben einer sofortigen weiteren Abklärung in kurzzeitigen Abständen kontrolliert werden.

Trotz der Verbesserungen bei der Erkennung aneuploider Zellmuster ist der Wert der Durchflußzytometrie zur Tumorentdeckung bei diploiden Zellproben weiter limitiert. Zur Verbesserung wird deshalb die Kombination der DNS-Analyse mit der Bestimmung anderer Zellparameter gefordert. Einer dieser möglichen Parameter ist das zelluläre prostataspezifische Antigen. Es wurde zwischenzeitlich eine Studie initiiert, in der im Rahmen einer Mehrparameter-Durchflußzytometrie neben dem Zellvolu- 
men, der Ploidiegrad und der zelluläre PSA-Gehalt in ganzen Zellen bestimmt werden. Hierzu wird die DNS mit Propidium Jodid markiert und das zelluläre PSA in einem indirekten Immunfluoreszenzansatz mit FITC-beladenen Antikörpern gemessen.
Ziel der Studie ist es zu überprüfen, ob die durchflußzytometrische Identifizierung von Prostatakarzinomzellen im Vergleich zur alleinigen DNS-Analyse durch die kombinierte Bestimmung von Ploidie und zellulärem PSA-Gehalt weiter verbessert werden kann. 